\title{
Women's Health Concern (WHC)
}

\section{What's your mission?}

We give information, advice and resources to women with gynaecological and sexual health problems, and raise awareness of those problems amongst doctors, nurses and the public at large. We are the only charity in this field offering a telephone helpline staffed by specialist nurses.

\section{How did you start?}

Our founder Joan Jenkins - nurse, filmmaker and media commentator realised that 'women's problems', like menstrual disorders and menopausal symptoms, were seen as something that women were expected to bear, even when they caused severe discomfort and life disruption. Jenkins was further motivated by her own mother's painful and untreated experiences during the menopause.

In 1972 Jenkins founded Women's Health Care; in 1980 it became a registered charity under the name Women's Health Concern (WHC). Other key figures involved in those early days were Wendy Moore, author of one of the first popular book on the menopause, No Change (1975), and Dr Gerald Swyer, the pioneer researcher on the contraceptive pill and hormone replacement therapy (HRT).

\section{What do you actually do?}

A large part of our work is dealing with client enquiries: we run an advice line every weekday morning and an e-mail enquiry service. Our website, recently redesigned, also offers a wide range of information leaflets and fact sheets, FAQs and useful links.

We also organise conferences and seminars for medical professionals twice a year. We've initiated a series of public forums for patients and their supporters, the first of which was in October 2007 and linked with World Menopause Day. Perhaps the most fun event we've run recently has been our charity gala evening featuring Menopause the Musical.

We increasingly comment on women's health to the press, particularly on issues such as HRT, endometriosis and sexually transmitted infections.

J Fam Plann Reprod Health Care 2008;

34(2): 132

\section{Cambridge, UK}

Susan Quilliam, BA, Cert Ed, MNLP, Freelance Writer, Broadcaster and Agony Aunt

Correspondence to: Ms Susan Quilliam. E-mail: susan@susanquilliam.com

\section{FURTHER INFORMATION}

Who: Women's Health Concern Ltd

Where: Whitehall House, 41 Whitehall,

London SW1A 2BY, UK

Contact: Tel: +44 (0)20 74511377 .

Fax: +44 (0)20 79251505

Telephone advice line: 08451232319

(Hours: 1000-1400 Monday/Tuesday,

1000-1300 Wednesday-Friday, local call rate)

E-mail advice:

info@womens-health-concern.org

Website: www.womens-health-concern.org

\section{Who is your typical client?}

There isn't one! Women of all ages and conditions contact us for advice and support about their own health or the health of partners, relatives or friends.

\section{What are typical client issues?}

The majority of client issues are around sexual health, female cancers and gynaecology. The top three problems, by percentage are: menopause and HRT $(38 \%)$, menstruation $(8 \%)$ and other gynaecological issues (11\%).

\section{How do clients find you?}

Some $38 \%$ of the calls to our advice line have heard of our services through the Internet. We also distribute advice line cards and posters to health centres and GP surgeries; $12 \%$ of callers have heard of our services through their GP, practice nurse or clinic. We don't have the budget for much event marketing, so we tend to advertise only our symposia, conferences and public forums.

\section{Who does the work?}

We have a team of eight part-time specialist nurse advisors who staff our telephone advice line and our e-mail enquiry service. A nurse advisor will typically receive $10-15$ calls in a day, and usually gives necessary advice directly, though in complicated cases she may refer to other nurse advisors or a specialist organisation. Nurse advisors always explain to women that advice from WHC isn't a substitute for a visit to their GP, but that it should be used in conjunction with support from health professionals.

Nurse advisors also represent WHC at meetings, road shows and exhibitions, helping to staff our information stands and giving face-toface advice. The nurse advisor team is backed by a team of 23 experienced medical advisors and a psychologist.

The leaflets and fact sheets are written by WHC staff and then reviewed by our medical advisors.

We also have a part-time administrative staff of four executives, supported by graduate interns on voluntary work experience. A typical day for our administrative staff might consist of working on the finances, fundraising, marketing, human resources issues and governance.

\section{How do you fit with other} organisations in the field?

We work closely with sister organisations; for example, we share information and expertise with the British Menopause Society and with WellBeing of Women. Most importantly, we direct clients to other organisations (e.g. Endometriosis UK) that cater for specialist needs.

\section{What are your biggest blocks to} development?

First, finance and publicity, the latter largely dependent on the former. In common with many health charities, we are heavily dependent on donations and much of our energy is spent in fundraising. Second, not overstretching the goodwill of our medical advisory panel, who despite the fact that they are all busy professionals, give their time and energy for free. Finally, the fact that as with any small charity, there are never enough hours in a day!

\section{What's been your biggest recent thrill?}

In 2006 WHC was highly commended by The Times and was number five in its 'Top Fifty Health Websites' survey: "Good women's health information is sparse on the Internet. This, from a counselling charity founded by a nurse, is one of the best - the fact sheets are clear and accessible".

\section{What are your plans and hopes for} the future?

Plans: we aim to extend the availability of our advice lines and our e-mail advisory service, as well as developing our website further. We also plan to run more conferences and public forums, in particular aiming to reach a wider variety of communities within the UK. Hopes: given wider financial backing, we would love to form a consortium of women's health charities to provide a campaigning voice on current female health issues.

\section{Editor's note}

This is the first in a series of occasional articles on key health organisations worldwide. The Journal would be pleased to hear from other organisations, particularly those based outside the UK, which would like to be similarly profiled. 